\title{
E-Referral System Modeling Using Fuzzy Multiple-Criteria Decision Making
}

\author{
Gandung Triyono, Sri Hartati, Reza Pulungan, Lutfan Lazuardi \\ Department of Computer Science and Electronics, Universitas Gadjah Mada, Yogyakarta, Indonesia \\ Department of Public Health, Faculty of Medicine, Universitas Gadjah Mada, Yogyakarta, Indonesia
}

\begin{tabular}{l} 
Article Info \\
\hline Article history: \\
Received Jan 2, 2018 \\
Revised Feb 23, 2018 \\
Accepted Apr 21, 2018 \\
\hline
\end{tabular}

Keywords:

Hospital

E-referral

FMCDM

Decision support system

\begin{abstract}
Currently, the quality of health services in Indonesia is getting better. However, referral systems still face many problems. The first is the difficulty in determining the referral hospitals based on patients' background and condition. The second is the many different parameters used to determine the referral hospitals between countries. Based on these issues, it is necessary to improve the current systems' capabilities. This study develops a model of an e-referral information system that takes into account patients' background. Some of the methods used in the model include information technology for patient care and Fuzzy Multiple-Criteria Decision Making to determine referral hospitals that fit patients' background. The result of this study is an intelligent system model to find referral hospitals that are most suitable to patients' backgound. In order to evaluate the model, we accumulate opinions of experts whether the output of the developed model matches the decisions taken by the experts. The evaluation indicates that the model obtains a conformity level of $81.45 \%$.
\end{abstract}

Copyright (C) 2018 Institute of Advanced Engineering and Science. All rights reserved.

\section{Corresponding Author:}

Gandung Triyono,

Department of Computer Science and Electronics,

Universitas Gadjah Mada, Yogyakarta, Indonesia.

Email: gandung.triyono@budiluhur.ac.id

\section{INTRODUCTION}

The development of information, telecommunication, and networking technologies has brought changes to health services. Utilization of information and communication technologies in the health service systems raises the term e-health. E-health is the use of information and communication technologies for the handling of patient health, such as patient care, community education, disease detection, public health monitoring, and referring patients [1].

At this time, health service industry has been progressing rapidly. However, the need for health services has not been fully met [2]. Adequacy of medical personnels and medical devices is a problem that requires serious handling. This problem causes the need to refer patients to better equipped health-care providers [3]. Referring patients from one health-care unit to other health-care units is called a referral system. A referral system is the organization of health services that regulates the delegation of duties and responsibilities of health services on both sides, vertical or horizontal. At this time, referral systems have made good progress, although they still face many problems.

Increasing population increases the need for health services, such as the need for medical personnels and medical devices. At this time, most of the specialist practitioners practice in large hospitals that exist in big cities. This leads to other problems. The first problem occurs for patients who reside away from urban areas as they need more time and cost $[4,5]$. The second problem is the difficulty to get a specialist according to the condition of the patient's illness $[6,7]$. The third problem is that there are delays arising from sending 
and queueing of patients at the general hospitals $[8,9]$. The fourth problem is that, for hospitalized patients, patients must wait for up to one month or until rejection from the hospitals $[3,10,11]$.

Besides, a doctor at the hospital often must perform re-examinations. This usually happens because the general practitioner at the primary health center often conducts referral without giving any initial examination, excludes the patient's medical record [12-14], and does not enclose the apparent reasons for referral [15]. These problems raise other problems, including: (1) the rejection by the hospital due to the incompatibility between the patient's illness with the physician's specialty, and (2) the patient treatment is delayed because the specialist has to perform re-examinations $[7,16]$.

In Indonesia, finding a referral hospital takes a long time: it takes more than 30 minutes to find the referral hospital. This is because doctors in primary health centers have to contact at least five hospitals to refer one patient [17]. Another problem that often occurs is the rejection of emergency patients by the hospital because of treatment room is not available [18], the referral hospital has no medical equipment, no specialist doctors, no referral letters from primary health centers [19], and patients cannot afford to pay the up-front payment [20]. Cipto Mangunkusumo Hospital (RSCM) receives more than 3,000 referral patients per day. Of these, only $30 \%$ of the patients go through the appropriate referral procedure [21]. The main cause of some of these problems is that referral systems in Indonesia have not functioned effectively [22, 23].

Some of the studies that have been done in the last few years provide solutions to overcome this problem of finding referral hospitals by developing an electronic referral system [7, 8, 16, 24-30]. The given solution is called e-referral system, which is an effort to improve the effectiveness of the referral process. However, most of the researches so far focused more only on referral communication, with the aim of facilitating the flow of patient referrals from one health-care unit to another.

Researches conducted in [29-32] developed intelligent system models that take into account the appropriateness between patients' health condition and the referral hospitals. Their researches resulted in systems that can be used to determine the referral hospitals by considering patients' health condition. However, these researches have not taken into account patient's economic background. An excellent ereferral system should consider patients' health condition and should also take into account patients' economic background. By taking into account these two conditions, the problems that exist in current ereferral systems can be overcome. Our current research aims at developing a referral system model that takes into consideration patients' health condition as well as economic background. The model is developed using Fuzzy Multiple-Criteria Decision Making (FMCDM) approach to find hospitals that fit the patients' background. Furthermore, web service technology is used in the communication between primary health centers and referral hospitals.

\section{RELATED WORK}

\subsection{Referral System Model}

The development of a referral system model that can determine referral hospitals based on patients' condition is complicated $[5,26]$. Determining the appropriate referral hospitals is influenced by many factors, such as patients' geographical location, the criticality of the medical situation, transportation, distance, and physical condition of the patients [29], as well as socio-economic of the patients [33]. Research conducted by [29] developed a referral system that is able to determine the exact referral hospitals specifically for patients with heart disease. Parameters used related to the patients include age, sex, nationality, type of treatment, disease severity, and type of payment. Parameters related to the hospital include hospital type, bed capacity, regional status, JCAHO (accreditation) status, operating ability, AMI termination volume, and CABG capability. However, the developed system is limited to emergency heart disease, distance, and time. The developed system only used experts as a reference, so that at any time the system needs to be re-adjusted if there are changes.

Several studies aimed at improving service quality in e-referral systems have been conducted in [28, 34, 35]. Their researches developed e-referral system models by replacing the use of telephone, fax, and reference request in hardcopy format into electronic one. The developed system model is already integrated into the Electronic Health Record (EHR) at several hospitals so that their units can easily access data. Unfortunately, their studies focused solely on switching hardcopy documents to electronics, hence, they have not been able to resolve current referral cases.

Also, [36] and [4] added facilities to the e-referral system. That facility is the ability to determine whether a patient is referred or not and the facility for consultation between a general practitioner and a specialist in the hospital. The facility can prioritize referrals and delay referral times until referral hospitals are ready to receive referral patients. The study might provide a solution to the referred patient without initial screening, however, the study focused only on advising whether a patient is referred or not. Meanwhile, our 
research adds a new facility to help general practitioner to choose the right hospitals based on patients' background.

\subsection{Referral System Model Using Web Services}

Web service is a technology that can be used for communication between applications from different platforms so that applications can integrate each other. Web service technology has been widely used as a solution on e-business [37,38]. One of the architectures for communication on web services is restful. Restful is an approach to web services that is easy to implement because it uses HTTP with rest principle. Restful is easy to implement, as simple as using HTML. Rest can also use XML or JSON to exchange data. Rest can differentiate messages because it analyzes the HTTP commands used during the request $[17,39,40]$. Besides, restful has main architectural aspects of addressability, statelessness, simple and similar interfaces, and multi-access [17, 39].

The research in [17] used web service technology to exchange information between primary health centers and hospitals. Web service technology is used to transmit medical record data to the hospitals and obtain information, such as availability of inpatient room, ICU room, specialist, and medical support equipment from the referral hospitals before sending a patient.

\subsection{Referral System Model Using FMCDM}

According to [41], Multiple-Criteria Decision Making (MCDM) is one way of making decisions based on analytical methods involving many criteria. A criterion is a value in the form of size, rule or standard used in the decision making. The problem in MCDM is the use of crisp sets because only small changes in a value lead to significant category differences. Therefore, MCDM is combined with fuzzy logic to solve the problem. Fuzzy MCDM can resolve the lack of precision in measuring the importance of criteria and alternative assessment of the evaluation criteria. FMCDM has been widely applied to address decisionmaking issues with multiple criteria and alternatives in a consistent, productive and systematic way [42-46].

Research that develops an intelligent system model that takes into account the appropriateness between the patients' health condition and the referral hospitals is quite rare, one of which is performed in [30]. The study developed a model of a referral system called Multi-Agent Referral Decision Support (MARDS). The model is developed using MCDM to determine the most appropriate referral hospitals. MultiAgent Provider System Selection technology is used to improve the quality of communication between general practitioners and hospitals. The fundamental difference of this research is the technology used for communication between primary health centers and hospitals. Also, the other difference is the criteria used. The current study adds insurance ownership criteria. Furthermore, this study also adds a facility to determine the type of treatment to patients.

\subsection{Parameters of E-Referral System}

The parameters used to determine referral hospitals in each country have different rules or policies. The differences can be seen in the previous studies in Table 1.

Table 1. Parameters of E-Referral Systems in Previous Studies

\begin{tabular}{|c|c|c|c|}
\hline Study & Country & Disease(s) & Parameters \\
\hline [29] & USA & $\begin{array}{l}\text { Acute Myocardial } \\
\text { Infarction } \\
\text { (AMI). }\end{array}$ & $\begin{array}{l}\text { Patient: age, gender, nation, type of treatment, disease } \\
\text { severity, type of payment. } \\
\text { Hospitals: hospital type, bed capacity, regional status, JCAHO } \\
\text { status (accreditation status), operating ability, AMI } \\
\text { termination volume, CABG capability. }\end{array}$ \\
\hline [7] & Canada & All diseases. & $\begin{array}{l}\text { Symptoms of patients, specialists, time availability, location of } \\
\text { specialists. }\end{array}$ \\
\hline [16] & Canada & All diseases. & $\begin{array}{l}\text { Gender, age, disability, general practitioner background, } \\
\text { practice and community background. }\end{array}$ \\
\hline$[6]$ & Nigeria & All diseases. & $\begin{array}{l}\text { Patient distance to hospital, patient's health condition, and } \\
\text { hospital facilities. }\end{array}$ \\
\hline [27] & Denmark & All diseases. & $\begin{array}{l}\text { Age, gender, ethnicity, marital status, diagnosis and } \\
\text { socioeconomic characteristics (such as income, education and } \\
\text { employment status). }\end{array}$ \\
\hline [47] & $\begin{array}{l}\text { Not } \\
\text { mentioned }\end{array}$ & Cancer in the elderly. & $\begin{array}{l}\text { Patients: age, patient's willingness, patient residence, } \\
\text { community, family, disease severity, clinical or biological } \\
\text { signs. }\end{array}$ \\
\hline [30] & Ethiopia & All diseases. & $\begin{array}{l}\text { Specialist doctors: specialist type, specialty quality, CPG. } \\
\text { Referral type, referral category, required services, hospital } \\
\text { location, hospital level, service waiting time and particular } \\
\text { referral type. }\end{array}$ \\
\hline
\end{tabular}


Table 1 show that seven studies discussing the search for hospitals or specialists for referrals in United States, Canada, Nigeria, Denmark, and Ethiopia. The diseases used for testing include acute myocardial infarction (AMI), cancers in the elderly, and all illnesses. Those seven studies were divided into three groups of parameters used, namely patients, doctors, and hospitals. Parameters related to patients include age, gender, type of treatment, severity of illness, type of payment, patient symptom, patient with special needs, community background, distance from patient to hospital, ethnicity, marital status, diagnosis, economic (education, income and employment status), comorbidity, patient's willingness, family willingness, clinical or biological signs, reference type, referral category, required services, and service waiting time. Parameters related to doctors include general practitioner's background, specialist type, and quality of specialization. Parameters related to hospitals include hospital type, bed capacity, regional status, hospital accreditation status, operational ability, AMI termination volume, CABG capability, and service waiting time.

In this study, we use ten parameters: insurance receipt, hospital ownership, length of waiting room of ward, availability of medical support, availability of specialist doctors, poly handling time, waiting time for handling of accident and emergency department, ease of transportation, distance between patient's residence and the hospital, and distance between the primary health center and the hospital. The parameters are used to determine referral hospitals that fit the patients' condition. In addition, this study also uses parameters such as age, gender, blood pressure, weight, blood glucose, comorbidity, pulse rate, eye awareness level, motoric awareness level, oral awareness level, systolic blood pressure, persistent fever, sudden hearing loss or vision, sudden paralysis, active bleeding, evisceration or wound diseases, vital signs monitoring, intramuscular/intravenous antibiotics every eight hours, use of continuous or intermittent respirators at least every 8 hours. Those seventeen attributes are used to determine the type of medical treatment. This type of medical treatment is performed in a poly room, department of accident and emergency, ICU, inpatient wards, or outpatient.

\section{PROPOSED MODEL}

This research was conducted in Yogyakarta, one of the provinces of Indonesia. The facts were found as follows. The referral systems are mostly still done manually, i.e., searching for available and suitable hospitals is conducted by phone.

The primary process in the current referral system consists of four sub-processes, namely: (1) Initial examination; conducted by medical personnels at a primary health center before referring a patient to a hospital. This preliminary examination is used to determine if the patient needs referring or not. (2) Determining the emergency level; which is the process to determine the severity of the patient's illness. The purpose of the process is to make it easier to determine the type of treatment provided at the referral hospital. Based in the type of treatment, the patient can be handled in poly, accident and emergency department, ICU, inpatient ward, or outpatient. (3) Searching of the hospital; which is conducted by medical personnels at the primary health center by phone. (4) Dispatching of a patient; if there is a hospital capable of handling, the medical personnels at primary health center will send the patient with referral documents. The referral documents can be a referral letter, lab results if any, and the result of the initial examination. The referral process from the primary health center to the hospital is depicted in Figure 1.

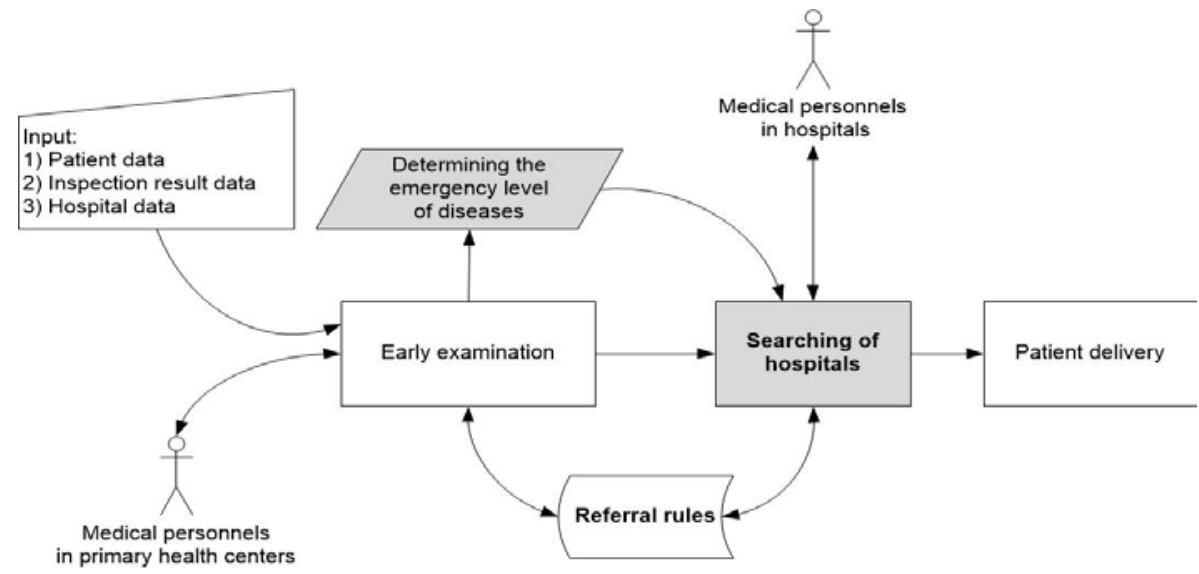

Figure 1. Referral process from primary health centers to hospitals 
Based on Figure 1, we propose a new model for the e-referral system, which comprises five main parts:

1. Interface; used by medical personnels at the primary health centers and the hospitals to interact with the referral system. The interface is developed using Java programming as Java supports multiplatform, is easy to develop, and dynamic. This part is illustrated in the Interface block in Figure 2.

2. Probabilistic Neural Network (PNN); which is used to determine the emergency level of diseases. The classification method used in determining the emergency level of diseases is an artificial neural network. This part is illustrated in the PNN block in Figure 2.

3. Web Service; which is used for searching referral hospitals. The searching process of the hospital is done by contacting many hospitals simultaneously. The service used is restful with the HTTP request method: Get, Post, Put, and Delete. JSON format is used in data transmission. In Figure 2, this part is illustrated by the Web Service block.

4. Rules are used to determine the appropriate referral hospitals based on the patient's condition. The rules is generated from the currently applied rules. As an example, for the case of a diabetic patient, if the patient is a Jamkesda insurance holder and the type of care is through Poly and the patient requires inpatient wards, then the selected hospital is of type C or D with class III treatment room. In another case of a patient with diabetes, if the patient is PBJS class I insurance holder, the type of care is through accident and emergency department and inpatient wards, then the selected hospital can be of type C, D, B or A with class I, II, or III treatment room.

5. FMCDM is used to provide a recommendation of referral hospitals to assist the medical personnel in the primary health center in the decision-making process. Fuzzy Multiple-Criteria Decision Making approach is used to provide the recommendation. The output is a list of hospitals that have been ranked based on the predetermined criteria. This part can be seen in the FMCDM block in Figure 2.

Figure 2 shows that the proposed referral system model has these abilities: (1) contacting several hospitals and receiving information from several hospitals simultaneously; (2) determining the type of treatment before dispatching the patient; and (3) assisting medical personnel in the primary health center to determine the referral hospital sbased on the patient's background condition. The focus of this work is to develop a model for the hospital ranking process based on the patient's background, by creating a framework for selecting referral hospitals that match the patient's background using FMCDM. According to [48], FMCDM is performed using the following steps: problem representation, evaluation of fuzzy sets of alternatives, and determine the rank of all alternatives, which will be elaborated on in the following.

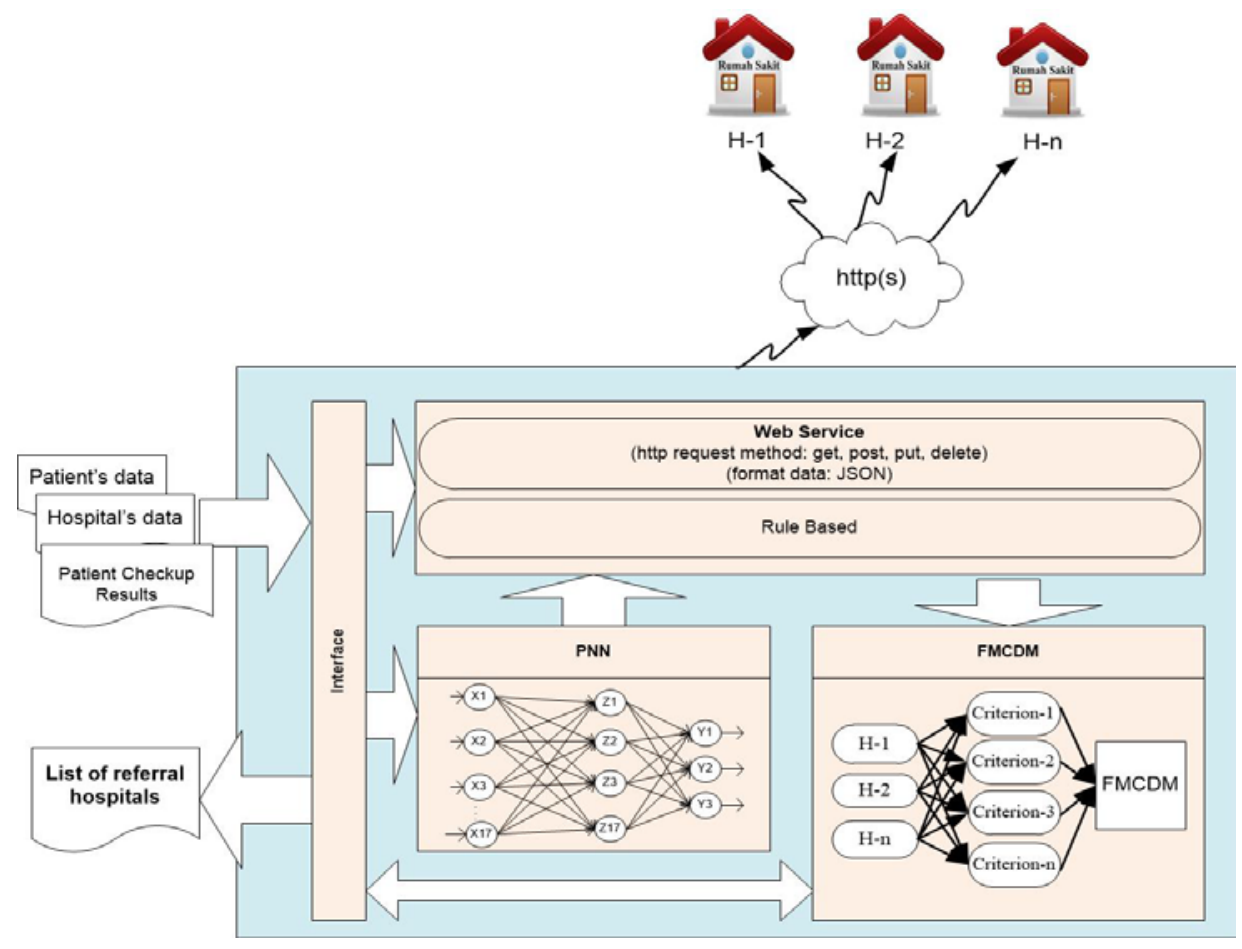

Figure 2. The proposed model of the e-referral system 


\subsection{Problem Representation}

In this step, there are three primary tasks. The first task is to provide a list of alternative referral hospitals that is appropriate to the patient's background, based on specified criteria. If there are $n$ alternatives (referral hospitals), then the set of alternatives can be denoted by $A=\left\{A_{i} \mid i=1,2,3, \ldots, n\right\}$. In this study, there are six alternatives, namely $A=\{$ RSU Permata Husada, RS Rajawali Citra, RSU Nur Hidayah, RSU PKU Muhammadyah Bantul, RSUD Panembahan Senopati, RSPAU Dr. Suhardi Harjolukito\}.

The second task is to determine the criteria used to rank the referral hospitals. If there are $k$ criteria for determining the choice of some alternatives, then the set of the criteria can be denoted by $C=\left\{C_{i} \mid i=1\right.$, $2,3, \ldots, k\}$. In this study, there are eleven criteria, namely $C=$ acceptance of insurance, hospital ownership, duration of waiting time in inpatient ward, availability of medical support, availability of Specialist, duration of waiting time in Poly, duration of waiting time in accident and emergency department, ease of transportation, duration of waiting time in ICU, distance between the patient's residence and the hospital, distance between the primary health center and the hospital . And the next task is determining the framework model of the referral hospital selection that is appropriate to the patient's background. The framework model is depicted in Figure 3.

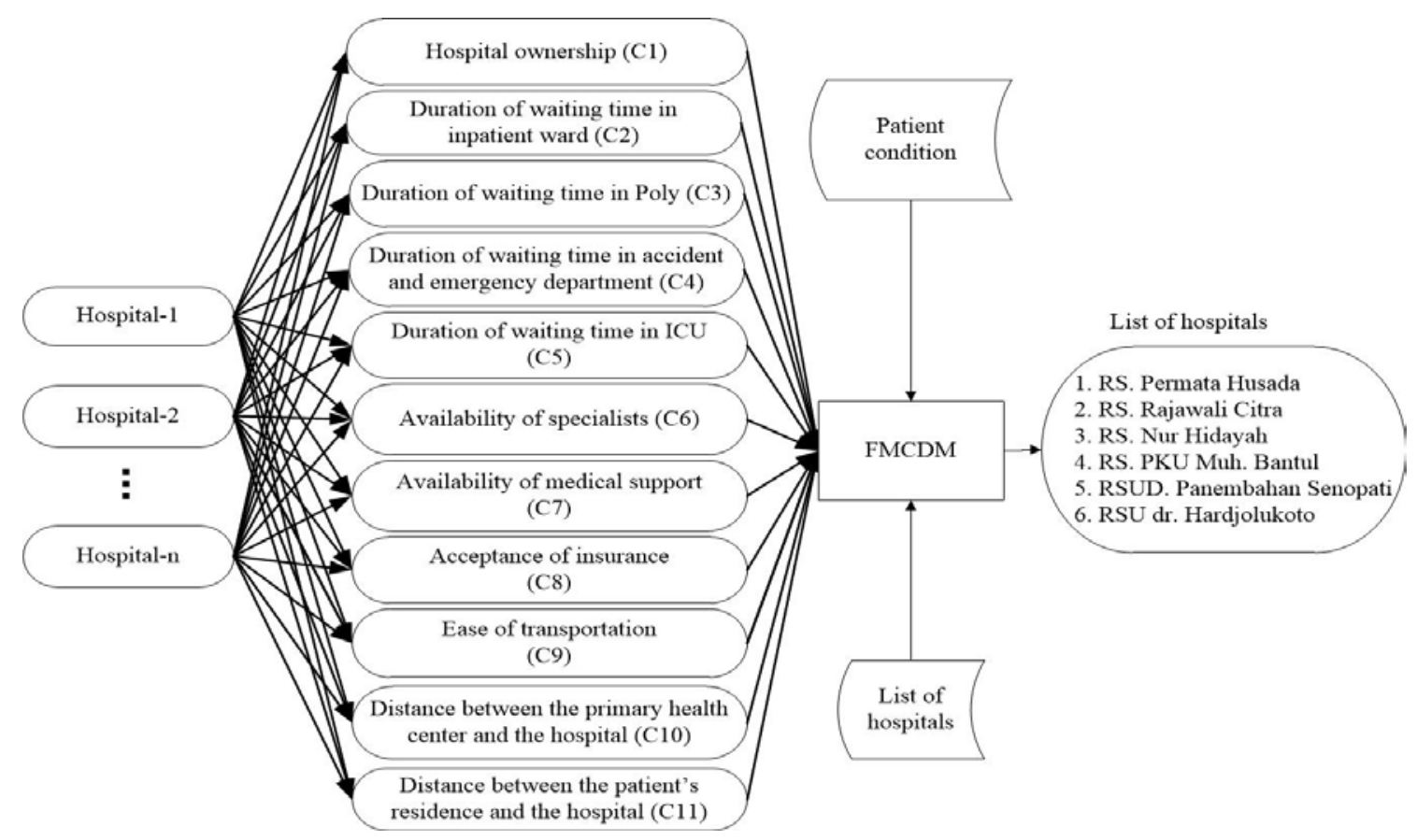

Figure 3. Decision-making framework of the e-referral's hospital selection

\subsection{Evaluation of Fuzzy Sets}

At this stage, an evaluation of the weight of each criterion is performed. In this study, we use the set of the fuzzy triangle in determining the membership function of the weights of criteria and the degree of compatibility of each alternative. For example, the membership function of the weight of a criterion to determine distance is depicted in Figure 4.

In determining the matching values, Equation (1), (2), and (3) are used:

$$
\begin{aligned}
& \mu_{\text {Near }}(x)=\left\{\begin{array}{c}
1 ; x \leq 4, \\
\frac{6-x}{6-4} ; 4 \leq x \leq 6, \\
0 ; x \geq 6,
\end{array}\right. \\
& \mu_{\text {Medium }}(x)=\left\{\begin{array}{c}
0 ; x \leq 4 \text { or } x \geq 10, \\
\frac{x-4}{7-4} ; 4 \leq x \leq 7, \\
\frac{10-x}{10-7} ; 7 \leq x \leq 10,
\end{array}\right.
\end{aligned}
$$




$$
\mu_{\text {Far }}(x)=\left\{\begin{array}{c}
0 ; x \leq 8, \\
\frac{x-8}{10-8} ; 8 \leq x \leq 10, \\
1 ; x \geq 10,
\end{array}\right.
$$

where $x$ is the actual distance and $\mu(x)$ is corresponding the membership function.

Afterwards, the selection of the membership function for an alternative degree of compatibility is carried out. In this case, five linguistic variables are used, namely Very Less (VL), Less (L), Quite Good $(\mathrm{QG})$, Good (G), and Very Good (VG). The weight of each variable is obtained from the fuzzy triangles, which can be observed in Table 2 .

Table 2. The Linguistic Variable and Its

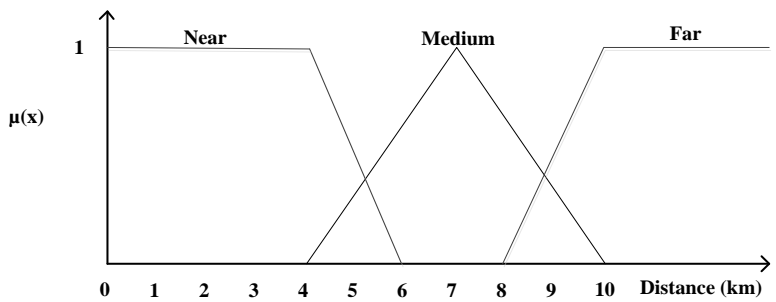

\begin{tabular}{ll}
\multicolumn{2}{c}{ Weight of Fuzzy Value } \\
\hline $\begin{array}{l}\text { Linguistic } \\
\text { variable }\end{array}$ & $\begin{array}{l}\text { Weight of the fuzzy } \\
\text { value }\end{array}$ \\
\hline VL & $(0.0,0.0,0.25)$ \\
L & $(0.0,0.25,0.50)$ \\
QG & $(0.25,0.50,0.75)$ \\
G & $(0.50,0.75,1.0)$ \\
VG & $(0.75,1.0,1.0)$ \\
\hline
\end{tabular}

Figure 4. Membership function using fuzzy triangles to determine distance

The linguistic variable is the used for the assessment of each criterion. After calculating the assessment of each criterion, the result as depicted in Table 3 is obtained.

Table 3. The Linguistic Variable and the Assessment of Each Criterion

\begin{tabular}{|c|c|c|c|}
\hline Criteria & $\begin{array}{l}\text { Linguistic } \\
\text { variable }\end{array}$ & Value & Weight of the fuzzy value \\
\hline \multirow[t]{2}{*}{ C1 } & Government (G) & 1 & $(1,1,1)$ \\
\hline & Private $(\mathrm{P})$ & 0 & $(0,0,0)$ \\
\hline \multirow[t]{5}{*}{ C2 } & Very Long (VL) & $(>16)$ & $(16,19,19)$ \\
\hline & Long $(\mathrm{L})$ & (11- 17 hours) & $(11,14,17)$ \\
\hline & Normal $(\mathrm{N})$ & (6-12 hours) & $(6,9,12)$ \\
\hline & Fast (F) & (1- 7 hours) & $(1,4,7)$ \\
\hline & Available(A) & ( $0-2$ hours) & $(0,0,2)$ \\
\hline \multirow[t]{3}{*}{ C3 } & Long (L) & (>25 minutes) & $((25,35,35)$ \\
\hline & Normal (N) & (10 - 30 minutes) & $(10,20,30)$ \\
\hline & Fast $(\mathrm{F})$ & $(0-15$ minutes $)$ & $(0,10,15)$ \\
\hline \multirow[t]{3}{*}{$\mathrm{C} 4$} & Long (L) & (> 25 minutes) & $(25,35,35)$ \\
\hline & Normal (N) & (10 - 30 minutes) & $(10,20,30)$ \\
\hline & Fast $(\mathrm{F})$ & $(0-15$ minutes $)$ & $(0,10,15)$ \\
\hline \multirow[t]{5}{*}{ C5 } & Very Long /Not Available(VL) & $(>16)$ & $(16,19,19)$ \\
\hline & Long (L) & (11- 17 hours) & $(11,14,17)$ \\
\hline & Normal (N) & (6-12 hours) & $(6,9,12)$ \\
\hline & Fast (F) & (1- 7 hours) & $(1,4,7)$ \\
\hline & Available (A) & ( $0-2$ hours & $(0,0,2)$ \\
\hline \multirow[t]{2}{*}{ C6 } & Not Available (NA) & 0 & $(0,0,0)$ \\
\hline & Available (A) & 1 & $(1,1,1)$ \\
\hline \multirow[t]{2}{*}{ C7 } & Not Available (NA) & 0 & $(0,0,0)$ \\
\hline & Available (A) & 1 & $(1,1,1)$ \\
\hline \multirow[t]{2}{*}{ C8 } & Not Available (NA) & 0 & $(0,0,0)$ \\
\hline & Available (A) & 1 & $(1,1,1)$ \\
\hline \multirow[t]{4}{*}{ C9 } & Very Difficult (NA) & (Not Available /Others) & $(0,0,0)$ \\
\hline & Difficult (D) & (Public $>=2$ times) & $(0.30,0.30,0.30)$ \\
\hline & Easy $(\mathrm{E})$ & (Public $<2$ times) & $(0.60,0.60,0.60)$ \\
\hline & Very Easy (VE) & (Private) & $(1,1,1)$ \\
\hline \multirow[t]{3}{*}{ C10 } & Far $(F)$ & $(\geq 8 \mathrm{~km})$ & $(8,10,10)$ \\
\hline & Medium (M) & $(4 \mathrm{~km}-10 \mathrm{~km})$ & $(4,7,10)$ \\
\hline & $\operatorname{Near}(\mathrm{N})$ & $(0 \mathrm{~km}-6 \mathrm{~km})$ & $(0,4,6)$ \\
\hline \multirow[t]{3}{*}{ C11 } & Far $(\mathrm{F})$ & $(\geq 8 \mathrm{~km})$ & $(8,10,10)$ \\
\hline & Medium (M) & $(4 \mathrm{~km}-10 \mathrm{~km})$ & $(4,7,10)$ \\
\hline & Near(N) & $(0 \mathrm{~km}-6 \mathrm{~km})$ & $(0,4,6)$ \\
\hline
\end{tabular}


As an example, a physician in a primary health center was requested to provide a weight for each criterion for the case of the referral patients handled at the ER and inpatient wards. Based on the linguistic variables in Table 2, the weighting result of each criterion for this particular physician is listed in Table 4.

Table 4. The Weight of Every Criterion

\begin{tabular}{lll}
\hline Criteria & Rating of interest & Weight of the fuzzy value \\
\hline C1 & VL & $(0.0,0.0,0.50)$ \\
C2 & G & $(0.50,0.75,1.0)$ \\
C3 & VL & $(0.0,0.0,0.25)$ \\
C4 & G & $(0.50,0.75,1.0)$ \\
C5 & VL & $(0.0,0.0,0.25)$ \\
C6 & VG & $(0.75,1.0,1.0)$ \\
C7 & VG & $(0.75,1.0,1.0)$ \\
C8 & VG & $(0.75,1.0,1.0)$ \\
C9 & VG & $(0.75,1.0,1.0)$ \\
C10 & L & $(0.0,0.25,0.50)$ \\
C11 & G & $(0.50,0.75,1.0)$ \\
\hline
\end{tabular}

\subsection{Ranking Alternatives}

The next process is to rate each alternative. Experiments are conducted using cases of patients with diabetes with the type of treatment through IGD and Inpatient Ward. After the input rating of each alternative matches each criterion, the next process is substituting the fuzzy number of each linguistic variable into (4), (5), and (6):

$$
\begin{gathered}
Y_{i}=\left(\frac{1}{k}\right) \sum_{t=1}^{k}\left(o_{i t} a_{i}\right), \\
Q_{i}=\left(\frac{1}{k}\right) \sum_{t=1}^{k}\left(p_{i t} b_{i}\right), \\
Z_{i}=\left(\frac{1}{k}\right) \sum_{t=1}^{k}\left(q_{i t} c_{i}\right),
\end{gathered}
$$

\begin{tabular}{|c|c|c|c|c|c|c|c|c|c|c|c|c|c|}
\hline \multirow{2}{*}{ No. } & \multirow{2}{*}{ Alternative } & \multicolumn{11}{|c|}{ Match rating } & \multirow{2}{*}{ Fuzzy match index } \\
\hline & & C1 & $\mathrm{C} 2$ & C3 & $\mathrm{C} 4$ & $\mathrm{C} 5$ & C6 & $\mathrm{C} 7$ & C8 & C9 & C10 & C11 & \\
\hline 1 & A1 & $\mathrm{P}$ & $\mathrm{N}$ & $\mathrm{L}$ & $\mathrm{F}$ & VL & $\mathrm{A}$ & A & $\mathrm{A}$ & $\mathrm{E}$ & $\mathrm{N}$ & $\mathrm{N}$ & $(0.51 ; 2.00 ; 4.86)$ \\
\hline 2 & A2 & $\mathrm{P}$ & A & $\mathrm{L}$ & M & VL & A & NA & A & VE & $\mathrm{N}$ & $\mathrm{N}$ & $(0.64 ; 2.00 ; 5.23)$ \\
\hline 3 & A3 & $\mathrm{P}$ & VL & $\mathrm{L}$ & M & VL & A & A & A & VE & $\mathrm{N}$ & $\mathrm{N}$ & $(1.37 ; 3.30 ; 6.77)$ \\
\hline 4 & A4 & $\mathrm{P}$ & $\mathrm{N}$ & $\mathrm{L}$ & $\mathrm{F}$ & VL & A & A & A & $\mathrm{E}$ & $\mathrm{N}$ & $\mathrm{N}$ & $(0.69 ; 2.27 ; 5.36)$ \\
\hline 5 & A5 & G & $\mathrm{L}$ & $\mathrm{L}$ & M & VL & A & $\mathrm{A}$ & A & $\mathrm{E}$ & $\mathrm{N}$ & $\mathrm{N}$ & $(1.38 ; 3.30 ; 7.16)$ \\
\hline 6 & A6 & G & $\mathrm{A}$ & $\mathrm{L}$ & M & VL & $\mathrm{T}$ & NA & A & $\mathrm{E}$ & $\mathrm{N}$ & $\mathrm{N}$ & $(1.41 ; 2.25 ; 5.80)$ \\
\hline
\end{tabular}

whose results are shown in Table 5.

Table 5. Assessment Indices for Every Alternative

After obtaining the fuzzy match index, the total integral is calculated by using (7):

$$
I^{\alpha}(J)=\left(\frac{1}{2}\right)(\alpha c+b+(1-\alpha) a)
$$

The resulting total integral value is used to rank alternatives. The results of the total integral and the ranking calculations are shown in Table 6. 
Table 6. The Total Integral Value of Each Alternative

\begin{tabular}{ccccc}
\hline \multirow{2}{*}{ No. } & \multirow{2}{*}{ Alternative } & \multicolumn{3}{c}{ Total integral value } \\
\cline { 3 - 5 } & & $\alpha=0$ & $\alpha=0.5$ & $\alpha=1$ \\
\hline 1 & A5 & 4.67 & 7.56 & 10.45 \\
2 & A3 & 4.66 & 7.37 & 10.07 \\
3 & A6 & 3.66 & 5.86 & 8.05 \\
4 & A4 & 2.97 & 5.30 & 7.64 \\
5 & A2 & 2.64 & 4.93 & 7.23 \\
6 & A1 & 2.51 & 4.69 & 6.86 \\
\hline
\end{tabular}

Based on Table 6, it can be concluded that alternative A5 is the alternative of the first order because it has the highest total integral value. Then, the next alternatives are A3, A6, A4, A2, and A1.

\section{RESULTS AND ANALYSIS}

To evaluate the proposed model, decisions generated by the model are compared to decisions taken by several experts. Experts in this case consist of medical personnels, such as doctors or midwives in primary health centers and hospitals. Likert Scale is used to assess the conformity of the model and the expert.

For the evaluation, a questionnaire is designed with eleven questions with five possible answers, namely Very Appropriate (VA), Appropriate (A), Quite Appropriate (QA), Inappropriate (IP), and Very Inappropriate (VI). The score of each answer is set as follows: VI $=1, \mathrm{IP}=2, \mathrm{QA}=3, \mathrm{~A}=4$, and $\mathrm{VA}=5$. The questionnaire is distributed to ten experts at primary health centers and hospitals. Table 7 shows the experts' answers to the questionnaire. Table 7 also indicates that the obtained conformity level (in

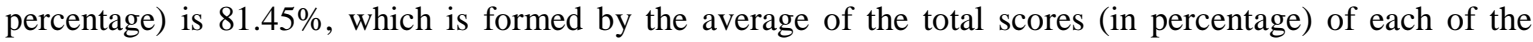
eleven questions in the questionnaire.

The first question is about the facility to obtain the medical record data of the initial examination results. The purpose of the question is to know whether the data used is by the needs of the referral system. The results obtained are one expert answered IP, five experts responded A, and four experts answered VA. Thus, the conformity result of this facility is $84 \%$. Hence, the facility can provide a solution for medical personnels of primary health centers to always perform initial examinations before sending patients to referral hospitals.

Table 7. Questionnaire Result

\begin{tabular}{|c|c|c|c|c|c|c|c|c|}
\hline \multirow{2}{*}{ No. } & \multirow{2}{*}{ Question } & \multicolumn{5}{|c|}{ Number of each response } & \multirow{2}{*}{$\begin{array}{l}\text { Total } \\
\text { score }\end{array}$} & \multirow{2}{*}{$\begin{array}{c}\text { Percentage } \\
\text { (\%) }\end{array}$} \\
\hline & & VI & IP & QA & A & VA & & \\
\hline 1 & Question 1 & 0 & 1 & 0 & 5 & 4 & 42 & 84.00 \\
\hline 2 & Question 2 & 0 & 0 & 0 & 6 & 4 & 44 & 88.00 \\
\hline 3 & Question 3 & 0 & 0 & 0 & 4 & 6 & 46 & 92.00 \\
\hline 4 & Question 4 & 0 & 0 & 1 & 7 & 2 & 41 & 82.00 \\
\hline 5 & Question 5 & 0 & 0 & 1 & 7 & 2 & 41 & 82.00 \\
\hline 6 & Question 6 & 0 & 0 & 2 & 5 & 3 & 41 & 82.00 \\
\hline 7 & Question 7 & 0 & 0 & 1 & 8 & 1 & 40 & 80.00 \\
\hline 8 & Question 8 & 0 & 1 & 0 & 9 & 0 & 38 & 76.00 \\
\hline 9 & Question 9 & 0 & 1 & 0 & 8 & 1 & 39 & 78.00 \\
\hline 10 & Question 10 & 0 & 1 & 0 & 8 & 1 & 39 & 78.00 \\
\hline 11 & Question 11 & 1 & 1 & 0 & 6 & 2 & 37 & 74.00 \\
\hline \multicolumn{2}{|c|}{ Average } & & & & & & & 81.45 \\
\hline
\end{tabular}

The purpose of the second question is to know whether sending preliminary examination data to several referral hospitals continuously can inform the patients' health condition more quickly. The results obtained are six experts answered A, and four experts answered VA. The conformity result is $88 \%$. The facility can solve the problem, so doctors at the hospitals do not have to conduct repeated examinations, and this can save time and cost.

The purpose of the third question is to find out the time it takes to contact a referral hospital. The results obtained are four experts answered A, and six experts answered VA, with conformity result of 92\%. It can be concluded that this facility can cope with contacting hospitals more quickly when compared to using the phone.

The purpose of the fourth question is to find out whether the information provided by the referral hospital is appropriate to the needs of medical personnel at the primary health center. The results obtained are 
one expert answered QA, seven experts answered A, and two experts answered VA. The percentage of conformity obtained is $82 \%$.

The fifth question is to know the criteria used to determine referral hospitals. The result obtained is that one expert responded QA, seven experts responded A, and two experts responded VA. The conformity result is $82 \%$.

The sixth question is to find out whether all the facilities in the developed model operate properly. The results obtained are two experts answered QA, five experts answered A, and three experts answered VA, so the conformity result is $82 \%$. It can be concluded that the existing facilities already operate properly.

The seventh up to the eleventh questions are to find out whether the resulting hospital recommendation conforms to the decision made by the experts. The five questions are for separate cases of patients. The first case is for patients with treatment through poly and outpatient. In this case, the conformity result produced by the developed model is $80 \%$. The second case is for patients with treatment through poly and hospital wards. In this case, the conformity result produced by the developed model is $76 \%$. The third case is for patients with treatment through emergency and emergency room. In this case, the conformity result produced by the developed model is $78 \%$. The fourth case is for patients with treatment through accident and emergency department and inpatient wards. In this case, the conformity result produced by the developed model is $78 \%$. The fifth case is for patients with treatment through accident and emergency department and ICU inpatients. In this case, the conformity result produced by the developed model is $74 \%$. The results obtained is in the range of $74 \%$ to $76 \%$ because there is one expert who responded inappropriate and one expert answered very inappropriate. The result is low because the experts have concerns that the recommended hospital cannot be changed. It should not be a concern because the resulting output is a list of approved hospitals so that medical personnels can still select from the recommended list of referral hospitals.

The ten experts who fill the questionnaire also provide a summary of the advantages of the developed system model as well as suggestions for improvement. The advantages of the developed model are that it is complete, according to current needs, and very helpful to solve existing problems. Suggestions from experts include the need for additional facilities to provide reasons for selecting the hospital, the need for support from the government, the need for confidentiality of patients' identity, and the need for scheduling if there are outpatients.

\section{CONCLUSION}

The main capability of the developed model is to provide referral hospital recommendations based on the patients' background. Recommendations are provided in the form of a list of referral hospitals based on FMCDM approach. Beside having this capability, the developed model is also equipped with facilities, such as modules to input preliminary examination data, to send preliminary examination data simultaneously to several hospitals, to request information from several hospitals simultaneously, and to determine the type of patients' treatment when referred to hospitals. The types of treatment include treatment of outpatients through Poly, Inpatient Ward through Poly or Outpatient through IGD, Inpatient Ward through IGD, or ICU Inpatient through IGD.

Based on the evaluation conducted, it can be concluded that the developed model conforms to the needs of e-referral. The conformity result of the developed model reaches $81.45 \%$ according to 10 medical personnels from primary health centers and hospitals. From the evaluation results, all the medics welcome positively the developed model for patients' referral from the primary health centers to hospitals. Some of their suggestions are more technical, such as: lost connection, power failures, and the government's involvement if it is to implement.

The future work of this study includes methods to classify the severity of the patients' disease. This classification aims to determine the type of treatment of patients when referred to the hospitals, so when the referral is conducted the type of treatment has been known.

\section{REFERENCES}

[1] Georgeff M. E-Health and the Transformation of Healthcare. South Melbourne, Australia; 2007.

[2] Saleem RM, Muhammad A, Martinez Enriquez AM. Remote Patient Monitoring and Healthcare Management Using Multi-Agent Based Architecture. Ninth Mex Int Conf Artif Intell. IEEE; 2010; 118-23.

[3] Kataria P, Juric R. Sharing e-Health Information Through Ontological Layering. 43rd Hawaii International Conference on System Sciences. IEEE; 2010; 1-10.

[4] Pires R, Jelinek H, Wainer J, Goldenstein S, Valle E, Rocha A. Assessing the Need for Referral in Automatic Diabetic Retinopathy Detection. IEEE Trans Biomed Eng. 2013; 60(12); 3391-8.

[5] Ulman S, Ray S, Raikar A. A Novel Application of the Osterwalder Model: Towards A Sustainable Ecosystem for Point of Care Technologies. IEEE Point-of-Care Healthcare Technologies (PHT). 2013; 16-8. 
[6] Abdullahi FB, Makurdi U. Design and Implementation of a Web-Based GIS For Patients Referral to Hospotals In Zaria Metropolis. IJRRAS. 2011; 8(July); 109-14.

[7] Almansoori W, Murshid A, Xylogiannopoulos F. K, Alhajj R, Rokne J. Electronic Medical Referral System: Decision Support and Recommendation Approach. IEEE 13th International Conference on Information Reuse \& Integration (IRI). IEEE; 2012; 572-7.

[8] Almansoori W, Zarour O, Jarada TN, Karampales P, Rokne J, Alhajj R. Applications of Social Network Construction and Analysis in the Medical Referral Process. IEEE Ninth Int Conf Dependable, Auton Secur Comput. IEEE; 2011; 816-23.

[9] Viberg N, Forsberg BC, Borowitz M, Molin R. International Comparisons of Waiting Times in Health CareLimitations and Prospects. Health Policy. Elsevier; 2013; 112(1-2); 53-61.

[10] Xu X, Li L. An Artificial Urban Health Care System and Applications. IEEE Transaction Intelligent Systems. 2010; 25(3); 63-73.

[11] Kim E-H, Linker DT, Coumar A, Dean LS, Matsen F a, Kim Y. Factors Affecting Acceptance of a Web-Based Self-Referral System. IEEE Trans Inf Technol Biomed. 2011; 15(2); 344-7.

[12] Mikai B. Miskomunikasi Picu Persoalan Dokter dan Pasien [Internet]. 2011. Available in: http://health.kompas.com/read/2011/06/28/1804198/Miskomunikasi.Picu.Persoalan.Dokter.dan.Pasien

[13] Guo M, Li B, Wu S. Effectiveness of Referral Incentive Policy: Exploring Using Queuing Network Model with Blocking. Service Systems and Service Management (ICSSSM), 8th International Conference on. Tianjin, China: IEEE; 2011; 1-6.

[14] Abel GA, Friese CR, Neville BA, Wilson KM, Hastings BT, Earle CC, Nancy L, Richardson Lisa C. Referrals for Suspected Hematologic Malignancy: A Survey of Primary Care Physicians. American Journal of Hematology. 2012; 87(6); 634-6.

[15] Singh H, Esquivel A, Sittig DF, Murphy D, Kadiyala H, Schiesser R, dkk. Follow-Up Actions on Electronic Referral Communication in A Multispecialty Outpatient Setting. J Gen Intern Med. 2010; 26(1); 64-9.

[16] Reinhart I, Dawoud K, Shafiq O, Alhajj R, Rokne J, Edworthy S. Electronic Medical Referral System: A ForumBased Approach. IEEE 13th International Conference on e-Health Networking, Applications and Services. IEEE; 2011; 185-8.

[17] Triyono G, Hartati S, Pulungan R, Lazuardi L. Referral Communication Model between Primary Health Centers and Hospitals Using Web Services. Cyberneticscom 2016. Makasar: IEEE; 2016; 1-6.

[18] Priharseno ZN. Satu Lagi, Bayi Meninggal Karena Ruang Rawat Penuh. Kompas. Jakarta; 2013.

[19] Nababan PS. Tak Bawa Surat Rujukan, Pasien Asma Dilarang Inap Pihak RSUD Duri. Kompas. Jakarta; 2014.

[20] Wahyudi. Ditolak 4 RS, Bocah Penderita Muntaber Meninggal. Sindonews. 2013.

[21] Poskotanews. IGD RSCM Selalu Kebanjiran Pasien. In http://poskotanews.com; 2013.

[22] Kompas. Pasien Terlantar, Sistem Rujukan Tidak Berfungsi. In 2008.

[23] Hermawan B. RSUD Dr Soetomo Overload karena Sistem Rujukan Salah [Internet]. RRI. 2013. Diambil dari: http://rri.co.id/index.php/berita/63924/RSUD-Dr-Soetomo-Overload-karena-\#.UsrbQfstlXM

[24] Vulto JCM, Louwman WJ, Poortmans PMP, Coebergh JWW. Hospital Variation in Referral for Primary Radiotherapy in South Netherlands. European Journal of Cancer. Elsevier. 2005; 41(17); 2722-7.

[25] Masseroli M, Marchente M. X-PAT: A Multiplatform Patient Referral Data Management System for Small Healthcare Institution Requirements. IEEE Trans Inf Technol Biomed. 2008; 12(4); 424-32.

[26] Ke W, Mostafa J. A Referral Approach to Finding Medical Informatics Reviewers. International Conference on Network-Based Information Systems. IEEE; 2009; 194-9.

[27] Højmark T, Rose K, Vedsted P. Association Between General Practice Referral Rates and Patients' Socioeconomic Status and Access to Specialised health Care A Population-Based Nationwide Study. Health Policy. 2009; 92; 180-6.

[28] Straus SG, Chen AH, Yee HF, Kushel JMB. Implementation of an Electronic Referral System for Outpatient Specialty Care. AMIA Annual Symposium Proceedings. USA: American Medical Informatics Association; 2011; 1337-46.

[29] Chi C, Street WN, Ward MM. Building a Hospital Referral Expert System with a Prediction and Optimization Based Decision Support System Algorithm. J Biomed Inform. 2008; 41; 371-86.

[30] Worku ZG. A Framework for Multi-Agent Referral Decision Support. Addis Ababa University; 2007.

[31] Omotosho A, Adegbola O, Adebo A. A Patient-Based Hospital Referral Decision Support System. Int J Comput Appl. 2016; 155(10); 38-43.

[32] Sun L, Yamin M, Mushi C, Liu K, Alsaigh M, Chen F. Information Analytics for Healthcare Service Discovery. $J$ Healthc Eng. 2014; 5(4); 457-77.

[33] Poulose JV, Health MP, Cert G, Care P. Association Between Referral-to-Death Interval and Location of Death of Patients Referred to a Hospital-Based Specialist Palliative Case Service. J Pain Symptom Manage. Elsevier; 2013; 46(2); 173-81.

[34] Daltayanni M, Wang C, Akella R. A Fast Interactive Search System for Healthcare Services. Annu SRII Glob Conf. IEEE; 2012; 525-34.

[35] Sworo GD, Kam M, Juan EJ. Design of a Telemedicine-Based System for Clinic-In-A-Can. IEEE Glob Humanit Technol Conf. IEEE; 2012; 265-70.

[36] Ansari AQ, Gupta NK, Ekata. Adaptive Neurofuzzy System for Tuberculosis. 2nd IEEE International Conference on Parallel, Distributed and Grid Computing. 2012; 568-73.

[37] Jin BJB, Zou DZD. Research of Web Service Based on P2P. Second Int Conf. on Commun Softw Networks, 2010; 412-5. 
[38] Mathkour H, Gannouni S, Beraka M. Web Service Composition: Models and Approaches. Proc 2012 Int Conf Multimed Comput Syst ICMCS. 2012; 718-23.

[39] Richardson L, Ruby S. RESTful Webservices. 1 ed. O’Reilly Media, Inc. United States of America: O’Reilly; 2007.

[40] Kanagasundaram R, Majumdar S, Zaman M, Srivastava P, Goel N. Exposing Resources as Web Services: A Performance Oriented Approach. Int Symp. on Perform Eval Comput Telecommun Syst (SPECTS), 2012. 2012; $1-10$.

[41] Zimmermann HJ. Fuzzy Set Theory and Its Aplications. 3 ed. London: Kluwer Academic; 1996.

[42] Chang T-H. Fuzzy VIKOR Method: A Case Study of the Hospital Service Evaluation in Taiwan. Inf Sci. Elsevier; 2014; 271; 196-212.

[43] Low C, Lin S. Fuzzy Multiple-Criteria Decision Making Model with Fuzzy Time Weight Scheme. TELKOMNIKA (Telecommunication, Computing, Electronics and Control). 2013; 11(11); 6831-40.

[44] Wong TT, Yang NY. Dependency Analysis of Accuracy Estimates in k-Fold Cross Validation. IEEE Trans Knowl Data Eng. 2017; 29(11); 2417-27.

[45] Fang Y, Chyu C. A Multicriteria Selection Model for Developing New Color Calibration Device. TELKOMNIKA (Telecommunication, Computing, Electronics and Control). 2014; 12(3); 2374-83.

[46] Bhattacharya S, Raju V. A Condorcet Voting Theory Based AHP Approach for MCDM Problems. Indones J Electr Eng Comput Sci. 2017; 7(1); 276-86.

[47] Delva F, Soubeyran P, Rainfray M, Mathoulin-Pélissier S. Referral of Elderly Cancer Patients to Specialists: Action Proposals for General Practitioners. Cancer Treat Rev. Elsevier; 2012; 38(7); 935-41.

[48] Kusumadewi S, Hartati S, Harjoko A, Wardoyo R. Fuzzy Multiple-Attribute Decision Making (Fuzzy MADM). 1 ed. Yogyakarta: Graha Ilmu; 2006. 